\title{
Improving Introductory Astronomy Education in American Colleges and Universities: A Review of Recent Progress
}

\author{
William H. Waller ${ }^{1, a)}$ and Timothy F. Slater ${ }^{2, b)}$
}

\begin{abstract}
Over the past 15 years, professional astronomers, their societies, and associated funding agencies have collaborated to improve astronomy teaching and learning at the introductory undergraduate level. Many nonscience majors and preservice teachers enroll in these introductory astronomy courses, thus meriting the focused attention. In this review of recent developments, issues, approaches, and resources, we describe and document key instructional assets that have been made available to college and university faculty who wish to enhance their teaching of introductory astronomy. We find that although faculty support has progressed intermittently, there exist numerous programs and resources that faculty can access to increase student engagement and learning in astronomy. As funding support for these various instructional assets have waxed and waned, the professional societies have served as vital anchors and agents for advancing the profession of astronomy education at the introductory undergraduate level. Our findings, though focused on astronomy education, can be applied to the practice of introductory undergraduate education throughout the Earth and space sciences.
\end{abstract}

(C) 2011 National Association of Geoscience Teachers. [DOI: 10.5408/1.3651408]

\section{INTRODUCTION}

Astronomy (like geology, oceanography, and meteorology) is commonly regarded as a gateway science, where many students gain their first introductions to investigating their natural environment via evidence-based reasoning. At the undergraduate level, approximately 250,000 students take an astronomy course each year in the United States (Fraknoi, 2001a). This amounts to one out of every ten full-time undergraduates, including future teachers, taking at least one course in astronomy during his or her college career (Fraknoi, 2001a; Partridge and Greenstein, 2004). As most of these undergraduate students are nonscience majors enrolled in a limited number of formal science courses, the introductory astronomy course often represents the last opportunity to engender among these students enhanced values for the scientific enterprise as an important part of the public interest. As such, helping college astronomy faculty become more effective teachers and stewards merits a high priority nationwide.

Approximately half of student enrollments in astronomy courses occur at community colleges and small 4-yr colleges (Fraknoi, 2001a), where the science faculty are often asked to teach astronomy as one of many science courses which they are teaching, and where until recently few opportunities have existed for professional development in astronomy education. Moreover, because these faculties teach a variety of courses, their own educational background may not necessarily be in astronomy. At both small colleges and large universities, many astronomy faculties are being asked to update their pedagogical skills and so evolve away from teaching as they may have been taught. Instead of delivering long and fact-filled lectures,

Received 7 December 2009; revised 29 November 2010; accepted 15 February 2011; published online 14 November 2011.

${ }^{1}$ Eureka Scientific and the Massachusetts Space Grant Consortium, 243 Granite Street, Rockport, Massachusetts 01966, USA

${ }^{2}$ University of Wyoming, College of Education, Laramie, Wyoming 82071,

USA

${ }^{a)}$ williamhwaller@gmail.com.

b) timslaterwyo@gmail.com. they are being encouraged to actively engage the students in learning science by thinking and acting as scientists [National Research Council (NRC), 2003; Slater, 2003; Slater and Adams, 2006]. The traditional approach, though often rich in content, has been found to be less than successful in creating positive learning outcomes among the students themselves (Slater, 2003; Prather et al., 2005). Given the recent progress in research-based forms of instruction, along with the continuing need for faculty to update their pedagogical skills, the field of college astronomy education is ripe for sustained professional support.

Thanks to pioneering efforts in astronomy education research, we now know a lot more about the ways students perceive-and misperceive-commonly experienced astronomical phenomena (Bailey and Slater, 2003, 2005; Sadler, 1996; Zeilik et al., 1998). We also have learned effective ways to engage students in confronting their perceptions and in working with scientific data as evidence to reconstruct their personal paradigms of physical reality (Slater et al., 2006; Prather et al., 2009). These cognitive and pedagogical advances have prompted new approaches to teaching undergraduate astronomy courses. Translating these research results and new approaches into improved classroom practice remains a key challenge for astronomy education specialists.

Beginning in the 1970s, the professional societies and funding agencies that serve the astronomical community became increasingly involved in this educational reform effort (Fraknoi and Wentzel, 1999). Through their own educational activities, and through synergies among these organizations, several programs and forums that support the professional development of college astronomy faculty have emerged nationwide. This review considers some of the early endeavors, follows a few prominent programs, and shows how a fledgling astronomy education reform movement has since blossomed into a multifaceted and abiding community of support for faculty at community colleges, small 4-yr colleges, and large research universities.

In the interest of brevity, the reflections contained herein are not meant to be comprehensive. For example, 
they do not address the considerable progress in undergraduate astronomy education that is being made on the international stage (see http:/ / www.iaucomm46.org). Nor do they provide adequate treatment of the education research that has done so much to inform and guide the teaching of astronomy (see http://astronomy.uwp.edu/ saber/). Instead, they focus on the pivotal roles that American professional societies and funding agencies have played to improve astronomy education at the introductory collegiate level. They also examine the ongoing issues in introductory astronomy education and review the associated approaches and resources that have been brought to bear on these issues.

Although we have focused on introductory undergraduate astronomy education, our general conclusions should be applicable to improving introductory undergraduate courses in any of the Earth and space sciences. Astronomy comprises an integral part of the Earth and space sciences, providing universal context for understanding our own planet's origin, evolution, and fate. As articulated below, many of the issues, approaches, and resources in introductory undergraduate astronomy education have parallels in the other Earth sciences.

\section{HISTORICAL BACKGROUND}

The professional development of astronomy faculty in American colleges and universities has a rich and complex history. It is beyond the scope of this commentary, however, to provide an exhaustive chronological review of all the various programs that have been developed to serve the pedagogical interests of these faculties. Indeed, such a chronology would be severely complicated by the fact that many of the professional development programs and their hosting organizations have been closely intertwined. While this intersection of activity has led to several synergies of mutual benefit, it makes a full historical accounting very difficult to carry out. Instead, the reader is directed to Table I, which lists some of the more prominent professional development programs and resources that have been provided over the past half-century. Prominent in this table are the venues created by professional societies, the American Astronomical Society (AAS), the Astronomical Society of the Pacific (ASP), and the American Association of Physics Teachers, among others.

The American Astronomical Society has served as a consistent home for addressing issues in college astronomy education since 1911, when it appointed a Committee on Cooperation in the Teaching of Astronomy (Fraknoi and Wentzel, 1999). The Society was particularly active in advancing undergraduate astronomy education during World War II, when "Teachers' Conferences" were regular parts of AAS meetings, and in the aftermath of Sputnik, when there was common concern that the United States was falling behind in science and technology. More recently, the AAS has hosted Astro 101 teaching excellence workshops at its biannual meetings, published the biyearly education newsletter Spark, instituted an Education prize, and assumed publication of the Astronomy Education Review (AER) - the journal of record in astronomy teaching and learning. In the first $5 \mathrm{yr}$ of its publication, $50 \%$ of the articles published addressed teaching introductory astronomy for undergraduate nonscience majors (Fraknoi and Wolff, 2007).

The Astronomical Society of the Pacific has had, since it founding in 1889, a long and distinguished record of increasing "the understanding and appreciation of astronomy by engaging scientists, educators, enthusiasts, and the public to advance science and science literacy" (see http://www.astrosociety.org/about.html). Through its educator workshops and conferences, the ASP continues to play a vital role in advancing formal, informal, and public astronomy education nationwide. At the Astro 101 level, its series of Cosmos in the Classroom symposia have had tremendous and long-lasting impact throughout the astronomy education community. The brainchild of Andrew Fraknoi (Foothill College), the series has been hosted by the ASP every 3 yr since its beginning in 1996. These symposia continue to be the premier venues for focused deliberation on astronomy education at the introductory collegiate level. The ASP has further instituted the only prize dedicated to college astronomy education - the Richard H. Emmons Award for Excellence in College Astronomy Teaching.

The National Science Foundation (NSF), being the primary funding organization for university-based scientific research and education in the United States, has promoted undergraduate astronomy education as part of its Course, Curriculum, and Laboratory Instruction (CCLI) program [recently changed to the Transforming Undergraduate Education in Science (TUES) program], GeoScience Education (GeoEd) program, and other related science education programs. From the mid-1970s to 2008, the NSF sponsored Chautauqua workshops for college faculty on a wide range of topics in science and mathematics. Each workshop typically lasted 3 days, with the participating faculty receiving partial compensation for their expenses. A significant number of these workshops were on astronomical topics, and ten of them in the last $7 \mathrm{yr}$ focused on introductory astronomy education. As of 2008, the NSF stopped direct funding of this vital program, leaving its survival uncertain at best.

Currently, the NSF is supporting a digital teaching library - the Community for Physics and Astronomy Education (COMPADRE-see http://www.compadre.org). Co-sponsored by the American Astronomical Society, American Institute of Physics, American Association of Physics Teachers, and other national physics organizations, COMPADRE provides a major online clearinghouse for teaching resources in physics and astronomy. The NSF also supports the Collaboration of Astronomy Teaching Scholars (CATS) - a CCLI program run by the Jet Propulsion Laboratory (JPL)'s Center for Astronomy Education (CAE) that is engaging selected astronomy faculty and students in a research study on the effectiveness of learner-centered astronomical instruction (see http://astronomy101.jpl. nasa.gov/). Publication of the Astronomy Education Review was originally funded by the NSF but has recently become part of the American Astronomical Society's formal suite of journals.

The National Aeronautics and Space Administration (NASA) has been engaged in space-related educational outreach since it was chartered in 1958. Between 1996 and 2006, NASA implemented a major program to engage college science faculty in the training of preservice teachers. The NASA Opportunities for Visionary Academics 
TABLE I: Professional development programs and resources for introductory astronomy instructors.

\begin{tabular}{|c|c|c|}
\hline Organization activity & Time period & References \\
\hline \multicolumn{3}{|l|}{ American Astronomical Society } \\
\hline Harlow Shapley Visiting Lectureships & 1960s-present & http://aas.org/shapley \\
\hline Goals for Astronomy 101 Workshops & 2001 & Partridge and Greenstein, 2004 \\
\hline Astro 101 Workshops $^{1}$ & 1999-present & http://astronomy101.jpl.nasa.gov/workshops/index.cfm \\
\hline Spark Education Newsletter & 2006-present & http://aas.org/education/spark_pubs.php \\
\hline Astronomy Education Review ${ }^{2}$ & 2009-present & $\begin{array}{c}\text { Fraknoi and Wolff, } 2007 \\
\text { http:/ / aer.aas.org }\end{array}$ \\
\hline \multicolumn{3}{|l|}{ Astronomical Society of the Pacific } \\
\hline Cosmos in the Classroom symposia & $\begin{array}{l}1996,1998,2000 \\
2004,2007,2010\end{array}$ & $\begin{array}{c}\text { Fraknoi, 2001b; Fraknoi, 2004; Fraknoi and } \\
\text { Waller, 2004; Fraknoi, 2005a; Fraknoi } 2007 \\
\text { http://www.astrosociety.org/events/cosmos.html }\end{array}$ \\
\hline $\begin{array}{l}\text { Richard H. Emmons Award for } \\
\text { Excellence in College Astronomy Teaching }\end{array}$ & 2006-present & $\begin{array}{l}\text { http:/ /astrosociety.org/membership/awards/ } \\
\text { emmons.html }\end{array}$ \\
\hline \multicolumn{3}{|l|}{ National Aeronautics and Space Administration } \\
\hline $\begin{array}{c}\text { NASA Opportunities for } \\
\text { Visionary Academics (NOVA) }\end{array}$ & $1996-2006$ & http://www.novaprogram.org/ \\
\hline $\begin{array}{l}\text { Center for Astronomy Education } \\
\text { (CAE) Teaching Excellence Workshops }{ }^{1}\end{array}$ & 2003-present & http://astronomy101.jpl.nasa.gov/workshops/index.cfm \\
\hline $\begin{array}{l}\text { Faculty Institutes for NASA Earth and } \\
\text { Space Science Education (FINESSE) }\end{array}$ & 2008-present & http://www.lpi.usra.edu/education/facultyInstitutes/ \\
\hline \multicolumn{3}{|l|}{ National Science Foundation } \\
\hline
\end{tabular}

${ }^{1}$ The Astro 101 workshops were originally hosted and funded by the AAS. Beginning in 2003, NASA's Jet Propulsion Laboratory has provided funding for the CAE and its Teaching Excellence Workshops which have since taken on the role of the Astro 101 workshops at meetings of the AAS and other venues.

${ }^{2}$ The Astronomy Education Review was originally hosted and funded by the National Optical Astronomy Observatories (NOAO), which itself is funded by the National Science Foundation (NSF). Beginning in 2009, the AER has been hosted and funded by the AAS.

(NOVA) program involved faculty and administrators from 106 colleges in professional development via 23 national workshops. The outcomes were more than 150 college-level science courses that were developed or modified to incorporate inquiry-based instruction. Approximately $40 \%$ of these courses included astronomy, planetary science, and/or space science. Assessment of these courses indicated significant improvement in the preservice teachers' content knowledge, improved attitudes toward the STEM subject, enhanced science process skills, and improved K-12 teaching efficacy (see http://www. novaprogram.org/). NASA funding of the NOVA program has since ended, leaving in limbo one of NASA's key programs for faculty professional development in spacerelated STEM disciplines.

Since 2003, NASA's Jet Propulsion Laboratory has sponsored the CAE, which runs Teaching Excellence workshops at community colleges nationwide. These workshops focus on dilemmas astronomy faculty often face and develop practical solutions for the challenging issues in curriculum, instruction, and assessment. The CAE also hosts the associated AstroLrner academic discussion group for college and university faculty (Slater, 2010).

In 2008, NASA's newly formed Science Mission Directorate (SMD) began its sponsorship of the Faculty Institutes for NASA Earth and Space Science Education (FINESSE). An outgrowth of NASA's Office of Space Science (OSS) Education and Public Outreach Program that ran from the mid-1990s to 2008 (Rosendhal, 2006), the FINESSE workshops provide a data-rich inquiry-oriented learning environment for science and education instructors of preservice teachers. The FINESSE website provides extensive resources for Earth and space science faculty who may (or may not) have preservice teachers in their classes (see http:// www.lpi.usra.edu/education/facultyInstitutes/).

As summarized in Table 1, our survey of the most prominent professional development programs for introductory astronomy college and university faculty - though admittedly incomplete-indicates two recurrent patterns. First, several of these programs have managed to persist, 
despite the inevitable changes in institutional support. Second, the professional societies have made key contributions to sustaining many of these programs. By providing welcoming venues for sharing interests, concerns, and assets in introductory undergraduate astronomy education, the societies have served as consistent "homes" for faculty wishing to improve their instructional skills.

\section{CURRENT ISSUES, APPROACHES, AND RESOURCES}

One major outcome of this educational reform effort has been a greater articulation of the challenges facing astronomy faculty and the solutions that have been developed in response. Herein is a representative sampling of the issues, approaches, and resources that have emerged in recent years.

\section{Classroom Strategies}

College courses in introductory astronomy can enroll as few as a half-dozen students up to more than 400 students (Fraknoi, 2005a). The resulting dynamics and classroom strategies can vary by similar degrees (Slater et al., 2006). In the last decade, considerable attention has been paid to address the daunting challenges of effectively engaging students in large astronomy classes. This has led to the development of many different techniques and strategies. These include lecture-tutorials that help students confront their misconceptions for true conceptual change (Brogt, 2007, 2008; Prather et al., 2005; Prather et al., 2009; Slater and Adams, 2006; Zirbel, 2004), peerlearning via initial questioning and "think, pair, share" dynamics (Green, 2003; James et al., 2008; Len, 2007; Slater et al., 2006), cooperative quizzes (Zeilik and Morris-Dueer, 2004a), weekly challenges (http://casa.colorado.edu/ \%7Edduncan/challenge.html), ranking tasks (Hudgins et al., 2007), role-playing games (Francis, 2006), the use of spatial and temporal models to convey key concepts (Taylor et al., 2003; http://www.cfa.harvard.edu/seuforum/ $\mathrm{mtu} /$ ), as well as lot of assessments that help both the students and their professors understand how they are faring in their respective roles as learners and educators (Bailey, 2006; Bardar, 2006; Bardar et al., 2006; Brogt et al., 2007; Hufnagel et al., 2000; Keller, 2006; Lindell, 2001; LoPresto, 2007). Though successful in large classes, most of these approaches can be tailored for use in small classrooms, where the teacher can spend more time on each student's learning (see Fig. 1).

Meanwhile, the issue of what should be taught in an introductory astronomy course continues to evoke controversy. Education researchers tend to emphasize the need to identify and confront the most basic misconceptions that students often hold (Bailey, 2006; Lindell, 2001; Sadler, 1996; Zeilik et al., 1998). Others are more concerned about conveying the story of modern space exploration and how it has informed our perceptions of the cosmos (Pasachoff, 2002). Still others advocate for a focus on night-sky literacy with an amateur astronomy emphasis (Jacobi et al., 2009; Waller, 2004). Although wide consensus on this issue remains unlikely, most astronomers seem to agree that effectively modeling the process of scientific inquiry is at least as important as providing specific science content

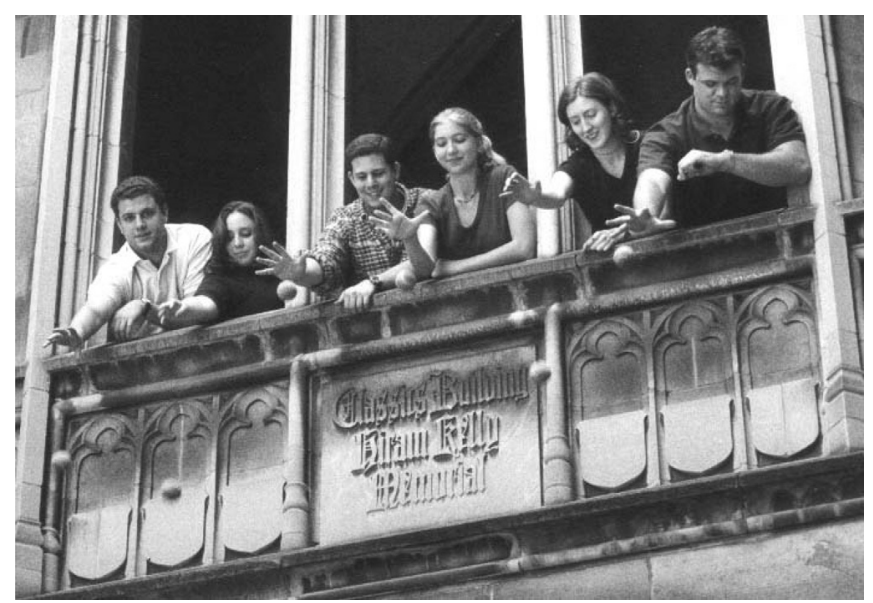

FIGURE 1: Getting students to take a more active role in their own learning is a key attribute of recent astronomy education reform efforts. For example, this student-initiated re-enactment of Galileo's experiment with falling objects was prompted by a conceptual "challenge" by the instructor which had the students actively predicting, explaining, and deliberating over what would happen (see http://casa.colorado.edu/\%7Edduncan/challenge.html). Photo courtesy of Douglas Duncan.

(Pasachoff, 2002; Partridge and Greenstein, 2004; Zeilik and Morris-Dueer, 2004a,b).

\section{Textbooks and Ancillary Materials}

All of the different approaches to classroom teaching of astronomy present tremendous challenges to the publishers of traditional, encyclopedic textbooks. What should be covered and how should the content be presented for optimal student learning? Despite these persistent challenges, most astronomy textbooks are remarkably similar in content and format. A survey of 23 textbooks for introductory undergraduate astronomy courses (Bruning, 2007) found that the average textbook has 604 pages, has a soft cover, and starts with the Solar System and works out to the universe as a whole (only three books order the topics the other way). Twenty-eight percent of the text is devoted to the Solar System (171 pages), $25 \%$ to stars (150 pages), $19 \%$ to galaxies and cosmology (117 pages), $15 \%$ to history and sky motions (93 pages), 9\% to light and telescopes (52 pages), and 3\% to astrobiology (18 pages). A few texts have additional chapters on modern physics. Texts average 15 pages of appendixes, 15 glossary pages, and 15 pages of index. Where these textbooks differ is in the various ways they engage the student in thinking and acting like scientists. Some of the different approaches, as summarized by the textbook authors themselves, are compiled in Bruning (2007).

Today's science textbooks represent multimillion dollar investments with huge multinational companies behind them. To remain competitive, the publishers now provide lots of ancillary material, including frequently updated websites for the students and complete lesson plans for the faculty (Bruning, 2006). They often incorporate the latest innovations, including live tutors, online tutorials, interactive applets, and copackaged personal response devices (aka "clickers") (Len, 2007). The textbook itself has become a small part of the overall cost. Whether or not this is a 
good thing in astronomy and the other Earth and space sciences depends on whether the added features are truly benefiting the faculty and their students.

To deliver a better and less expensive product - and to foster greater brand loyalty - publishers often seek out astronomy faculty to provide more input on their classroom teaching goals, to encourage their students to read the assigned textbook(s), and to discourage the reselling of their used books back to the campus bookstore. Meanwhile, the state of astronomy textbook publishing is in as much flux as the publishing of most print media. As the electronic components of astronomy textbooks become increasingly important, licensing arrangements may provide the best solution to reducing overall costs while ensuring adequate compensation for the publishers and their authors (Fraknoi, 2005b).

\section{Online and Other Digital Resources}

Since its development in 1990, the world-wide web has become one of the most important venues for teaching introductory Earth and space sciences, including astronomy. Free online textbooks are now available (see for example http://astronomynotes.com), and a variety of online courses in astronomy are being offered. For faculty, Swinburne University and James Cook University in Australia provide postgraduate courses in astronomy that can inform and enrich one's teaching (see http://astronomy. swri.edu.au/sao and http://www.jcu.edu.au/eps/). Many other online and digital resources in college-level astronomy education have been compiled recently by the Astronomical Society of the Pacific at http://www. astrosociety.org/education/resources/educsites02.html. Other online astronomy resources are intended for use by "citizen scientists" but can be helpful to college faculty seeking ways to engage students in exploring their physical environment. These include Google Earth, Google Moon, Google Mars, Google Sky, Stellarium, and the World-Wide Telescope.

Beyond the effective delivery of scientific content and pedagogy, one of the most striking trends in education technology has been the increasing use of "clicker" response devices, personal digital assistants (PDAs), and even cell phones as mediators of information between the teacher and student (Len, 2007). While these new technologies have many virtues, they also have several pitfalls. Most common among them is the tendency for curriculum developers to deliver old content in new wrappers (e.g., electronic textbooks and PowerPoint lectures), what has been termed "Shovelware" by e-learning advocates such as NSF Distinguished Teaching Scholar Chris Impey (University of Arizona). At their best, these new technologies will enable "universities without walls," where one can be a student anytime and anywhere-with seamless guided access to real datasets and engaging activities in astronomy.

\section{Observatories and Planetaria}

Given today's context of abundant and easily accessible information on astronomy, one might conclude that observatory and planetarium experiences have been superceded. The use of observatories and planetaria in teaching introductory astronomy appears to be more a matter of access than choice, however. At the introductory level, campus observatories can provide a qualitative but vital benefit, in that the visual telescopic experience makes the scientific subject more "real," vivid, and fun. The inspirational moment of seeing Saturn's rings for the first time is often cited by students (Waller, 2004). More quantitative laboratory exercises with telescopes are certainly possible at the introductory level but tend to work best for the more advanced students. At all levels, students engage in the scientific process by making their own astronomical observations (see Fig. 2). Introductory courses have been developed that fully integrate observatory experiences, laboratory exercises, textbook reading, and classroom interactions. By scheduling class times at night and by designing the classroom to serve as the laboratory workspace, instructors can closely link the observational and analytic strands of the course (cf. Waller, 2004). Research on the educational efficacy of observational "laboratories" show modestly positive results but also reveal issues relating to logistical challenges of serving
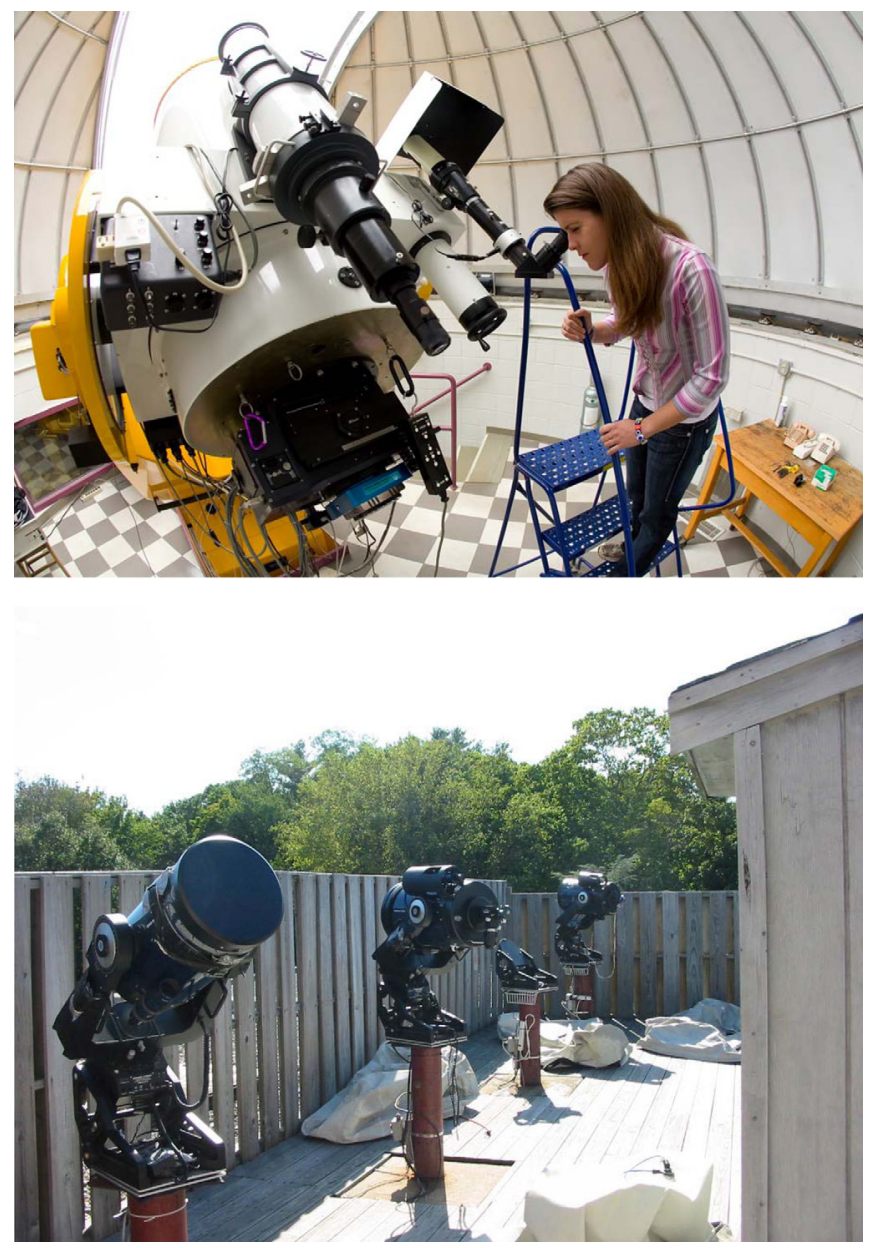

FIGURE 2: (Color online) Campus observatories can enable memorable hands-on, eyes-on learning experiences for college students enrolled in introductory astronomy courses. The observing facilities can consist of (top) classic domed structures housing one or more telescopes and/or (bottom) more distributed telescopic facilities without an enclosure - the latter enabling modest initial investment. Photos courtesy of (top) Jay Pasachoff and Megan Bruck (Williams College) and (bottom) Tim Barker (Wheaton College). 
large numbers of students in variable weather circumstances (Jacobi et al., 2009).

For those without direct access to an astronomical observatory, remote observing is available through the free MicroObservatory portal (http://mo-www.cfa.harvard. edu/OWN/), the emergent Las Cumbres Observatory Global Telescope Network (http://lcogt.net/), and the commercial SLOOH facilities (http://www.slooh.com/ about.php). Observational projects based on archival data have grown in number and sophistication - from the timetested Contemporary Laboratory Experiences in Astronomy (CLEA) (http://www3.gettysburg.edu/ marschal/ clea/CLEAhome.html) to the SkyServer activities hosted by the Sloan Digital Sky Survey (http:/ / cas.sdss.org/dr7/ en/). These and many other observing projects suitable for Astro 101 students are listed at http://www.compadre. org/astronomy/index.cfm.

The benefits of using a planetarium derive from its ability to portray the celestial sphere as it is actually seenfree of distortions inherent to planar mappings and unencumbered by weather and light pollution constraints. Star patterns and relative brightness become more familiar. Instructors with access to a planetarium can vivify concepts of the meridian, the ecliptic, equatorial coordinates, diurnal motion, lunar motion and phases, the dance of the planets, and the effects of varying latitude in ways that would be otherwise impossible. Although many public planetarium presentations tend to be one-way affairs with very little engagement by the attendees, this communication barrier can be broken by the instructor through the judicious use of education technologies such as "clickers" (cf. Grice, 2004; LaSala, 2004).

\section{Support for Teaching Teachers}

An astonishing 18\% of students enrolled in colleges (and hence in introductory science courses) find employment in the education sector-mostly as K-12 teachers [National Center for Education Statistics (NCES), 2003]. Over a 20-yr career, each of these educators could reach 500 to 2500 students. Given such impressive numbers, these teachers in training will have tremendous impact on the scientific education of the next generation of Americans. Yet they are typically underserved by the standard introductory undergraduate survey course on astronomy, where the content knowledge may be too watered-down relative to their science backgrounds, and pedagogical issues are completely ignored. Future conferences and other faculty professional development programs in undergraduate astronomy education would do well to focus on the effective education of these preservice science teachers.

NASA has been addressing this challenge since 1995, with its Pre-Service Teacher Institutes (see http://www. nasa.gov/offices/education/programs/descriptions/PreService_Teacher_Institutes.html), which hosts conferences and longer institutes for undergraduate preservice teachers, as well as the NOVA program, which served the faculty of preservice teachers between 1996 and 2006. Currently, the FINESSE is the only major NASA program providing astronomy- and geoscience-related professional development for those science and education faculty who are preparing the next generation of teachers (see http:/ / www.lpi.usra.edu/education/facultyInstitutes/). Given the FINESSE program's limited scope (serving only a few dozen faculty per year) and finite (5-yr) funded lifetime, considerably more could and should be done to assist faculty who teach courses in the Earth and space sciences with preservice $\mathrm{K}-12$ teachers in them.

\section{CONCLUSIONS}

In the last $15 \mathrm{yr}$, a robust community of professional support for college astronomy faculty has taken root. Unique to this effort, no entity, agency, or institution has single-handedly provided all the needed resources to make this system-wide support network function. Instead, a number of key organizations have helped to amplify fledgling programs that had been created and championed by a few energetic individuals. The professional astronomical societies, in particular, have done the most to infuse these programs throughout the broader college astronomy teaching community. A major benefit of this approach is its longevity. As NSF funding is reallocated, as NASA's major missions and initiatives phase in and out, and as NASA itself reorients its educational programming, the societies continue to do their vital work. No doubt, the presence or absence of NSF, NASA, or other support can have major effects on a society's dossier of educational programs. Nevertheless, the professional societies can provide the most secure long-term "homes" for advancing educational reform. Through the work of one's professional societies, it is possible to transcend one's individual lack of resources and collectively build-up a healthy community of ongoing instructional support.

These conclusions should pertain to administrators, scientists, and faculty in other scientific disciplines as well-including all of the geological, geophysical, oceanographic, meteorological, and astronomical sciences that collectively make up the Earth and space sciences. In the geosciences, in particular, progress in introductory undergraduate education is being pursued by the American Geological Institute (AGI), American Geophysical Union (AGU), Geological Society of America (GSA), International Geoscience Education Organization (IGEO), and National Association of Geoscience Teachers (NAGT) - the hosts of the JGE (see http://www.geoscied.org/). We applaud their endeavors and encourage their members to make the most of the educational assets that they have developed.

\section{Acknowledgments}

We thank Erin Dokter, Andrew Fraknoi, and Bruce Partridge for their comments and other helpful input.

\section{REFERENCES}

Bardar, E.M., 2006, Development and analysis of spectroscopic learning tools and the light and spectroscopy concept inventory for introductory college astronomy [Ph.D. Dissertation], Boston University, AAT 3214908.

Bardar, E., E.E., Prather, K., Brecher, K., and Slater, T.F., 2006, The need for a light and spectroscopy concept inventory for assessing innovations in introductory astronomy survey courses: Astronomy Education Review, v. 4, no. 2, p. 20-27.

Bailey, J.M., 2006, Development of a concept inventory to assess students' understanding and reasoning difficulties about the properties and formation of stars [Ph.D. Dissertation], University of Arizona, AAT 3206918. 
Bailey, J.M., and Slater, T.F., 2003, A review of astronomy education research: Astronomy Education Review, v. 2, no. 2, p. 20-45.

Bailey, J.M., and Slater, T.F., 2005, Resource letter on astronomy education research: American Journal of Physics, v. 73, no. 8, p. 677-685.

Brogt, E., 2007, A theoretical background on a successful implementation of lecture tutorials: Astronomy Education Review, v. 6 , no. 1 , p. 50-58.

Brogt, E., 2008, Instruction as a scientific experiment: A professional development case study of a professor changing the introductory astronomy course for non-science majors: Astronomy Education Review, v. 6, no. 2, p. 20-31.

Brogt, E., Sabers, D., Prather, E.E., Deming, G.L., Hufnagel, B., and Slater, T.F., 2007, Analysis of the astronomy diagnostic test: Astronomy Education Review, v. 6, no. 1, p. $25-42$.

Bruning, D., 2006, Survey of introductory astronomy textbooks: Astronomy Education Review, v. 4, no. 2, p. 54-90.

Bruning, D., 2007, Survey of introductory astronomy textbooks: An update: Astronomy Education Review, v. 5, no. 2, p. 182-216.

Eror, N., 2001, NSF Chautauqua short courses: A professional development bonanza: Journal of College Science Teaching, v. 30, no. 5, p. 290-291.

Fraknoi, A., 2001a, Enrollments in astronomy 101 courses: An update: Astronomy Education Review, v. 1, no. 1, p. 121-123.

Fraknoi, A., editor, 2001b, Cosmos in the classroom: A symposium on teaching astronomy for non-science majors: San Francisco, CA, Astronomical Society of the Pacific.

Fraknoi, A., 2004, Insights from a survey of astronomy instructors in the community and other teaching-oriented colleges in the United States: Astronomy Education Review, v. 3, no. 1, p. 7-16.

Fraknoi, A., 2005a, Education matters: Cosmos in the classroom 2004: Mercury, v. 34, no. 2, p. 11.

Fraknoi, A., 2005b, Astronomy textbooks, used book chains, and big macs: A perspective: Astronomy Education Review, v. 4, no. 1, p. $145-149$.

Fraknoi, A., editor, Cosmos in the classroom 2007: A hands-on symposium on teaching introductory astronomy: San Francisco, CA, Astronomical Society of the Pacific.

Fraknoi, A., and Wentzel, D., 1999, Astronomy education and the American Astronomical Society, in DeVorkin, D.H., editor, The American Astronomical Society's first century: Washington, D.C., American Astronomical Society (AAS) and American Institute of Physics (AIP), p. 194-212.

Fraknoi, A., and Waller, W.H., editors, 2004, Cosmos in the classroom 2004: A hands-on symposium on teaching introductory astronomy: San Francisco, CA, Astronomical Society of the Pacific.

Fraknoi, A., and Wolff, S., 2007, Astronomy education review: A five-year progress report and thoughts about the journal's future: Astronomy Education Review, v. 5, no. 2, p. 1-4.

Francis, P., 2006, Using role-playing games to teach astronomy: An evaluation: Astronomy Education Review, v. 4, no. 2, p. 1-9.

Green, P.J., 2003, Peer instruction for astronomy: Upper Saddle River, NJ, Pearson Education.

Grice, N., 2004, Using the planetarium for teaching introductory astronomy, in Fraknoi, A., and Waller, W., editors, Cosmos in the classroom 2004: San Francisco, CA, Astronomical Society of the Pacific, p. 161-162.

Hudgins, D.W., Prather, E.E., Grayson, D.J., and Smits, D.P., 2007, Effectiveness of collaborative ranking tasks on student understanding of key astronomy concepts: Astronomy Education Review, v. 5, no. 1, p. 1-2.
Hufnagel, B., Slater, T., Deming, G., Adams, J., Lindell Adrian, R., Brick, C., and Zeilik, M., 2000, Pre-course results from the astronomy diagnostic test: Publications of the Astronomical Society of Australia, v. 17, p. 2-18.

James, M.C., Barbieri, F., and Garcia, P., 2008, What are they talking about? Lessons learned from a study of peer instruction: Astronomy Education Review, v. 7, no. 1, p. 37-43.

Jacobi, J.C., Newberg, H.J., Broder, D., Finn, R., Milano, A.J., Newberg, L.A., Weatherwax, A.T., and Whittet, D.C.B., 2009, Effect of night laboratories on learning objectives for a nonmajor astronomy class: Astronomy Education Review, v. 7, no. 2 , p. 66-73.

Keller, J.M., 2006, Development of a concept inventory addressing students' beliefs and reasoning difficulties regarding the greenhouse effect [Ph.D. Dissertation], University of Arizona, AAT 3237466.

LaSala, J., 2004, Using the planetarium in teaching an introductory astronomy course, in Fraknoi, A., and Waller, W., editors, Cosmos in the classroom 2004: San Francisco, CA, Astronomical Society of the Pacific, p. 129-130.

Len, P.M., 2007, Different reward structures to motivate student interaction with electronic response systems in astronomy: Astronomy Education Review, v. 5, no. 2, p. 5-15.

Lindell, R.S., 2001, Enhancing college students' understanding of lunar phases [Ph.D. Dissertation], University of Nebraska, Lincoln, AAT 3022646.

LoPresto, M.C., 2007, Astronomy diagnostic test results reflect course goals and show room for improvement: Astronomy Education Review, v. 5, no. 2, p. 16-20.

National Center for Education Statistics (NCES), 2003, A descriptive summary of 1999-2000 bachelor's degree recipients 1 year later with an analysis of time to degree, v. 5, no. 3, see http:// nces.ed.gov/programs/quarterly/vol_5/5_3/4_3.asp.

National Research Council (NRC), 2003, Evaluating and improving undergraduate teaching in science, technology, engineering, and mathematics: Washington, D.C., National Academies Press, see http:/ / www.nap.edu/catalog.php?record id=10024.

Partridge, B., and Greenstein, G., 2004, Goals for "Astro 101": Report on workshops for department leaders: Astronomy Education Review, v. 2, no. 2, p. 46-89.

Pasachoff, J., 2002, What should college students learn?: Astronomy Education Review, v. 1, no. 1, p. 124-130.

Prather, E.E., Slater, T.F., Adams, J.P., Bailey, J.M., Jones, L.V., and Dostal, J.A., 2005, Research on a lecture-tutorial approach to teaching introductory astronomy for nonscience majors: Astronomy Education Review, v. 3, no. 2, p. 122-136.

Prather, E.E., Rudolph, A.L., and Brissenden, G., 2009, Teaching and learning astronomy in the 21st century: Physics Today, v. 62 , no. 9 , p. $41-47$.

Rosendhal, J.D., 2006, Creating NASA's space science education and public outreach program: The real stuff (abridged): Mercury, v. 35 , no. 6 , p. 20-29.

Sadler, P., 1996, Astronomy's conceptual hierarchy, in Percy, J.A., editor, Astronomy education: Current developments, future coordination, Astronomical Society of the Pacific Conference Series: San Francisco, CA, Astronomical Society of the Pacific (ASP), v. 89, p. 46.

Schatz, D., Fraknoi, A., Robbins, R.R., Smith, C.D., and Knappenberger, P.H., Jr., 1978, Effective astronomy teaching and student reasoning abilities: A workshop (preface), Berkeley, CA, Regents of the University of California.

Slater, R.F., 2003, When is a good day teaching a bad thing?: The Physics Teacher, v. 41, no. 7, p. 438-438.

Slater, T.F., Prather, E.E., and Zeilik, M., 2006, Strategies for interactive engagement in large lecture astronomy survey classes, in Mintzes, J.J., and Leonard, W.H., Handbook of college science teaching: Arlington, VA, National Science Teachers Association Press, p. 45-54. 
Slater, T.F., and Adams, J.P., 2006, Learner-centered astronomy teaching: Strategies for ASTRO 101: Upper Saddle River, NJ, Prentice-Hall.

Slater, T.F., 2010, AstroLrner E-community: A ten year retrospective: Astronomy Education Review, v. 9, no. 1, p. 010601.

Taylor, I., Barker, M., and Jones, A., 2003, Promoting mental model building in astronomy education: Journal of International Science Education, v. 25, no. 10, p. 1205-1225.

Waller, W.H., 2004, Using a campus observatory for effective teaching, in Fraknoi, A., and Waller, W., Cosmos in the classroom 2004: San Francisco, CA, Astronomical Society of the Pacific, p. 213-215.
Zeilik, M., Schau, C., and Mattern, N., 1998, Misconceptions and their change in university-level astronomy courses: The Physics Teacher, v. 36, no. 2, p. 104-107.

Zeilik, M., and Morris-Dueer, V.J., 2004a, The impact of cooperative quizzes in a large introductory astronomy course for non-science majors: Astronomy Education Review, v. 3, no. 1, p. 51-61.

Zeilik, M., and Morris-Dueer, V.J., 2004b, What are essential concepts in "Astronomy 101"? A new approach to find consensus from two different samples of instructors: Astronomy Education Review, v. 3, no. 2, p. 61-108.

Zirbel, E.L., 2004, Framework for conceptual change: Astronomy Education Review, v. 3, no. 1, p. 62-76. 